\title{
Innovation \& Its Diffusion in Business: Concept, Stages \& Procedural Practices
}

\author{
* Dr. Muhammad Tariq Khan, Associate Professor \\ ** Dr. Tariq Iqbal Khan, Assistant Professor (Corresponding Author) \\ *** Dr. Shiraz Khan, Assistant Professor
}

\begin{abstract}
Innovation is a new idea, object, or practice like scientific knowledge, technical products, application method, and tools which are viewed as new facilitators of problem-solving, on-the-spot acceptance, procedure, community, structure, and technology. The number of research in the field of economics have determined that innovation is about creation as well as the adoption of new business models, new product and services. Technological innovations are especially important because they drive the progress of societies. In a competitive business setting, enterprise and entrepreneur or business leaders should continuously pursue new openings/opportunities and make the needed arrangements for converting them into new products, goods, and services. But a new idea scientific method, product, practice, application method, and the tool does not turn out to be an innovation until adopted broadly and integrated into diffusion "a special type of communication process comprising some stages by which an innovation is communicated through certain channels over time among the members of a social system". This paper attempts to clarify in depth the concept of creativity and its distribution to consumers or adopters.
\end{abstract}

Keywords: Innovation, Technology, New Products

\section{Introduction}

Innovation is an object, idea, or practice to which individuals or adoption units perceive as new (Inman, 2000) and centers on the process, people, technology, structure, and culture (Okpara, 2007). Innovation can be defined as creating a new product, offering a new service, or initiating a new process, new ideas, and new stages in the organization. The organization must bring changes in all processes; it may change in one or more but should be aligned with the company's core business and vision. New ideas should be tested before commercialization so one can find the pros and cons of this idea. Innovation puts new ideas to commercial use and leads to the development of new technologies $\&$ products, and also drives economic growth. However, the best measure of innovation's economic consequences is productivity growth, and economists have concluded that innovation, the creation \& adoption of new business models, products \& services is a key to enhancing prosperity \& improving living standards (Atkinson \& Wial, 2008). Global competition \& technology forces have brought an upheaval that urges the associations to look through better approaches to rehash themselves. Innovation is a key factor underlying the competitiveness of a country (Ling \& Nasurdin, 2010). Innovation and creativity are building blocks of development in any organization. So it's very important to invest in this domain to get a competitive advantage and remain updated in this rapidly changing environment.

All innovations have a strong effect on every aspect of firm life. Organizations achieve competitive advantage by managing effectively for today and tomorrow by creating innovation. So for the firms, it is important to have innovation a part of competitive advantage building (Abou-Moghli et al., 2012). Therefore in an environment of competitive business, it is a must for enterprise \& entrepreneur to seek out new opportunities continuously and make essential arrangements for converting them into new products \& services. Therefore the innovation should impregnate the whole enterprise to invent \& create relevancy and competitive edge in the marketplace (Okpara, 2007). Innovation has a potential role in strengthening social cohesion \& social development as well.

\footnotetext{
* Department of Management Sciences, The University of Haripur Email: tariq_phd@ yahoo.com

** Department of Management Sciences, The University of Haripur Email: tariqfirst@ gmail.com

*** Department of Management Sciences, The University of Haripur Email: shirazkhan@uoh.edu.pk
} 
Innovation can contribute to public policies to lively democracies to engage active and knowledgeable citizens and also holds the potential to contribute to prevent the marginalization of specific groups.

Innovation literature emphasizes the learning role in the innovation process (Shapiro et al., 2007), but innovation, if not adopted, is perceived as useless. Therefore maximizing the adoption rate by diffusion of innovation is one of the duties of those responsible for innovation (Chiagona \& Licker, 2008). Innovation diffusion is the process of adoption initially by a few members of a social system and then adoption by more members over time and finally adoption by almost all the members (Valente, 1996). The objective of this study is to discuss various aspects of innovation such as elements, their classification, and their diffusion, factors affecting different in the public (Hana 2013).

\section{Literature Review Innovation}

Hana (2013) revealed that Schumpeter first time used the term "Innovation" at the start of the twentieth century and defined innovation as: "product, process \& organizational change that do not necessarily originate from new specific discoveries, but many arise from a combination of already existing technologies \& their application in a new context."

Mohammad \& Backhouse (2014) quoted an innovation definition by Kotler (1991) as: "innovation is any good, service or idea that someone feels as new." As indicated by Robertson (1967), advancement is a cycle whereby another thing or conduct or a novel idea is thought about and brought into the real world.

Inman (2000), Robinson (2009), Sahin (2006), and Stephenson et al. (2017), quoting Rogers asserted that innovation is an object, idea, or practice that is perceived as new by a unit of adoption or an individual. Innovation, instead of any mechanical creation can be an idea; it must be integrated \& perceived to have value. Similarly, Chigona and Licker (2008) expressed that a product or a concept is an innovation if it is perceived as new by adopters. Therefore an innovation doesn't need to be new, but instead of this, it must be supposed as new.

Sahin (2006) also similarly highlighted the newness of innovation that "an innovation may have been innovated a long ago, however, if individuals still perceive it as new, then for them it is still an innovation. The characteristic of the newness of innovation is related to three steps, i.e.' knowledge, persuasion \& decision' of adoption-decision process".

Tolba and Mourad (n.d.) uncovered that advancements are new logical information, specialized items, instruments, and application techniques that encourage the arrangement of the issue for likely appropriation. Various adopters of advancement evaluate and see developments in various manners. Bertrand (2004) quoted several examples of successful 'Diffusion of Innovation' (DoI) such as new prescription drugs, hybrid corn, family planning, modern math, etc. Okpara (2007) stated that innovation is a process that brings the best ideas into reality and triggers a creative idea causing to generate chain or series of innovation events. Innovation is new value creation. Innovation is the implementation of creative inspiration and a process of transforming new ideas into new values or combining ideas and knowledge in new values because, without this, an enterprise and its products rapidly become obsolete. It is the foundation of competitive advantages, the way of fulfilling the requirements of customers, and also a technology using method. Okpara (2007) describes innovation as "the intersection of invention and insight, leading to the creation of social and economic value". Innovation needs another perspective on, getting individuals and their innovative eagerness to face the challenge and buckle down because new ideas do not become innovation unless it is adopted widely $\&$ incorporated in the daily life of people.

Ling and Nasurdin (2010) expressed that organizational innovation is regarded as the adoption of new behavior/ new notion to adopting organization. Thus innovation can take the form of new production process technology, new product or service, new program or plan about members of organization, new administrative system or structure.

Abou-Moghli et al. (2012) asserted that innovation is a mental process leading to a new phenomenon may be a spiritual product or new material. Innovation is analyzing and combining some concepts and creating new concepts and new thinking not available previously. For firms, it is a critical factor for value creation and sustaining competitive advantage in high dynamics \& complex environment. Firms accepting innovation and responding to environmental changes, developing new capabilities enabling them for achieving higher performance will be highly successful. 
Musa (2012), mentioning the formula "Invention-innovation- diffusion mechanism," expressed that technological changes happen by a three chain relationship. "Innovation is an additional creativity improving the usefulness and features of an invented product." "Diffusion is the spreading of technological knowledge into different streams of economic activities that widens space for further creativity to amplify the chain system of invention, innovation \& diffusion."

Hana (2013) expressed that innovation also originated from public research. Therefore it is possible to summarize that according to these definitions, innovation covers technical \& technological changes \& improvements and particular practical applications originating from research. Imaginative exploration work and human resources are viewed as significant determinants of advancement. The imaginative cycle is partitioned into two vital parts. One section is imaginative, which is related to unique thoughts, concepts, or thought generation - and the second is innovative, which encompasses the implementation \& marketing of the invention.

Akram et al. (2011) and Almedia et al. (2017) stated that innovation is a process \& practice which acquires, captures, manages \& diffuses knowledge aiming to create new knowledge that will support delivering and produce idiosyncratic \& distinctive kind of products \& services. Innovation's fundamental aim is to create value for a business. So innovation in the present era of competition is a soul to business because organizations are required to make unique products possible only through innovation. Innovation is also important due to rapid changes in the preferences \& tastes of customers.

Bitter-Rijpkema et al. (2003) expressed that continuous innovation aiming to stay ahead of competitors and satisfy the customer's changing needs is key to success in business.

Murray (2009) elaborated that diffusion's final results are adoption, implementation \& institutionalization. An organization or an individual 1 - adopts innovation by taking a decision, 2 implements the diffusion by testing and putting it in practice, \& 3 - institutionalize innovation by fully supporting \& putting it incorporating it in routine practice.

\section{Re-invention}

According to Sahin (2006), Re-invention is "the degree to which an innovation by its user is modified or changed during the adoption \& implementation process." As per Mark and Poltrock (2001), a development once received, might be utilized uniquely in contrast to what had been utilized when the client learned or started to utilize it the first time. This cycle is termed as re-invention. Re-invention refers to changing the technology itself, while interest is focused on how the technology use may have changed to support various collaboration types. Sahin (2006) pointed out that usually, re-invention occurs at the usage stage, so it is a significant aspect of this stage. Raban and Koren (2012) portrayed that the re-creation idea was presented in the 1970s in Diffusion of Innovation (DoI) and characterized as "the degree to which, users modify an innovation in adoption \& implementation process." Reinvention widens the available choices to potential adopters. Innovation modification or selective rejection of some innovation components can also occur instead of either adoption or rejection. On innovation, most research is conducted in the implementation stage, which is the fourth stage. Information re-invention occurs when individuals modify it expressing their creativity (Sengphet, Hui, \& Phong, 2019; Vargas-Hernandez, \& Gonzalez, 2020). Organizations that are focusing only day on day matters face the consequences of not to re-invent. Sooner or later, organizations need to re-invent or modify their process and products to remain in the business, especially organizations that are in the maturity phase of their business. This is the process that differentiates top-performing organizations from low performing organizations. In a new era, most of the organization are learning this technique to become more efficient. So research in this area needs an hour.

\section{Elements of Innovation}

Okpara (2007) concluded that innovation is successfully developing a competitive advantage, which means it is key to entrepreneurship. Entrepreneurs take responsibility for innovation, and innovation distinguishes them from others. Accordingly, development must build intensity through endeavors focusing on restoration, revival, and redefinition of starts, their enterprises, or their business sectors if organizations are viewed as pioneering. Okpara (2007) referenced Fiona Fitzpatrick, who distinguished the following innovation elements - "9 Cs.

1 - $\quad$ Creativity: Generating \& sharing the ideas-the "brain"

2 - Communication: The flow of ideas \& information - the "lifeblood"

3- $\quad$ Challenge: What we are trying to change or accomplish-the "pull."

4 - Customer focus: Creating values for customers - the "push" 
5 - $\quad$ Completion: implementing the new ideas-the "muscle"

6 - Collaboration: people coming together to work together on the ideas - the "heart."

7 - $\quad$ Contemplation: Learning \& sharing lessons lead to higher competency-the "ladder"

8 - $\quad$ Culture: The playing field on innovation includes:

(i) - $\quad$ Leadership (sees the possibilities \& positions the team for action-the role model)

(ii) - People (diverse groups of radically empowered people innovate-innovation sources)

(iii) - Basic values (trust $\&$ respect, define \& distinguish an innovative organization-the breakthrough)

(iv) - Innovation values (certain values stroke the fires that make the "impossible" possiblethe spark)

9 - $\quad$ Context: Innovation is shaped by interaction with the world"".

Ling and Nasurdin (2010) expressed that organizations viable in information the board see information as a benefit for developing organizational values \& norms supporting their employees to acquire, share \& apply knowledge necessary for innovation activities. Ling and Nasurdin (2010) also asserted that a high level of knowledge management effectiveness is one method of improving organizational performance \& innovation. Bitter-Rijpkema et al. (2003) expressed that innovative companies need professionals who are creative and provide innovative solutions, which are the heart of success. Due to globalization, organizations are recruiting a diverse workforce, which is one of the basic elements for innovation and creativity. To keep a diverse workforce creative and innovative, the organization needs to create a conducive work environment. Cultural intelligence also plays a vital role in the creative performance of employees, so while hiring new employees, management should consider cultural intelligence.

\section{Classification of Innovations}

Robertson (1967) developed below given representative conceptual framework to classify innovations as per their effects on recognized patterns: (1) Continuous innovations, (2) Dynamically continuous innovations \& (3) Discontinuous innovations.

(1) - Continuous innovations have the least disruptive influence on established patterns.

Product alteration is involved instead of establishing a new product, such as new models of automobiles; fluoride toothpaste; menthol cigarette.

(2) - Dynamically continuous innovations have more disrupting effects though generally it does not alter establish patterns. It involves the alteration of existing products along with the creation of new products, such as the Mustang automobiles; electric toothbrushes; Touch-tone telephones.

(3) - Discontinuous innovations involve establishing a new behavior pattern and establishing a new product, such as cell phone; computers; television, vaccine.

Ling and Nasurdin (2010) categorized innovation as administrative \& technological. Some researchers classified organizational innovation into three types: administrative innovation, process innovation \& product, innovation. Some researchers classified innovations according to productionprocess, product or service, people \& organizational structure. According to innovation and organizational size, there are six types of innovations i.e. process, 'product or service', administrative, radical, technical \& incremental. Some other researchers categorized as: new production methods, new supply sources, new market, new organizing ways, new product \& new services.

Remear (2014) mentioned two kinds of innovations 1- sustaining innovation \& 2 - disruptive innovation. Remear (2014) argued that disruptive innovation helps in making another market and worth organization and upsets a current market and worth organization replacing earlier technology, and - improves products \& services in unexpected ways that for market firstly by designing in a new market for a different set of customers, and secondly by reducing prices in the existing market. Disruptive innovations let the economies and firms to grow by creating new businesses \& developing new product markets. Disruptive innovation provides consumers with products that were out of access for them previously, by reducing technology costs for providers and users. Sustaining in contrast creates no new market or value networks. Instead of doing this sustaining innovation develops existing business sectors with better worth, and permitting the organizations to contend with each other against continuing enhancements. Sustaining innovations can be continuous (i.e. "evolutionary") or discontinuous (i.e. "revolutionary" or "transformational").

Okpara (2007) and Abou-Moghli et al. (2012) mentioned the following types of innovation: 
1 - Innovation in firms made or offered products or services. If reformist development is overwhelming, revolutionary advancement opens up a new market, prompting increment in viable interest, which empowers the expansion in speculation and business.

2 - Innovation in processes, an improvement \& change in methods of products making or service offering which lowers costs, increases productivity \& demand.

3 - Innovation in work association and the board, and misuse of human assets, alongside the ability to foresee methods.

Akram et al. (2011) pointed out two kinds of innovation 1- radical innovation \& incremental innovation. Radical innovation is the products, processes \& services entirely significant \& unique improvement in their existing features improving performance and costs. Radical innovation for the business is highly risky because the commercialization of radical innovated products is very difficult. However radical innovation involves the development \& application of new, advance, and sophisticated technology. Incremental innovation is the modification in the products also called market pull or line extension innovation and it needs not to diversify significantly from current business. This type of innovation causes to enhance the competencies and skills of the employees of the organization. This innovation helps the organizations to enhance their market share for remaining for a long time in the industry.

Ling and Nasurdin (2010) expressed that there is also an administrative form of innovation which is the ability of firms to new: rules \& procedures, social structure, communication network, and rewards \& information systems are very important because productive managerial cycles lead cost proficiency and better business execution. In an assembling setting, as advancement in regulatory cycles can cause cost-effectiveness, it is worthwhile to investigate the predictors of administrator innovation. Ling and Nasurdin (2010) further narrated that administrative innovation refers to performance derived by alteration in administrative process \& organizational structure, information system. "Administrative innovation is a key source of competitive advantage because manufacturing organizations operate on internal process efficiency basis".

\section{Social Innovation}

Researchers also identified another type of innovation that is social innovation and as per The Young Foundation (2012) among researchers, foundations, policymakers, and academic institutions, there is growing interest in social innovation around the world. Social innovation has no common or shared definition. However several definitions are in circulation and boundaries around social innovation are ill-defined and very vague. By its temperament, social development is multi-disciplinary and cuts across fields of activity and areas. Social development likewise has risen as a reaction of developing demographical, ecological, and social difficulties generally named as 'mischievous' issues since they are multi-faceted complex, include endless partners, and essentially are difficult to illuminate.

Macvaugh and Schiavone (2010) quoted an example of medical innovation that in what way social contagion inside users' community can intercede the elements of new item reception. describe:

The Young Foundation (2012) explained that social innovation term has been broadly used to

- $\quad$ Societal transformation

- $\quad$ Social entrepreneurship

- A model of organizational management

- $\quad$ A model of governance, empowerment, and capacity building

- $\quad$ The development of new programs, products \& services

Social innovation first has used to describe the process of social transformation as a whole and social change

Akram et al. (2011) stated that bringing innovation is the foremost purpose of knowledge management. For bringing innovation \& getting the sustainable competitive advantage organizations across the organizational boundaries can develop the collaboration which would help the organization to approach the new knowledge and ultimately bringing the innovation causing reduction in cost and risk.

\section{Innovation Diffusion}

According to Inman (2000), Bertrand (2004), and KOCAK et al. (2013) diffusion is a process of communication of innovation, over time through certain channels among the social system members. 
Diffusion is the process wherein innovations are adopted and gain acceptance in certain community members. "Diffusion is a peculiar type of communication wherein message is about new ideas". Diffusion is grounded as much in anthropology as in psychology and as much in agriculture as education. Diffusion has four key components i.e. innovation itself, time, social system, and communication channels. From a business viewpoint, according to Peres et al. (2010) diffusion of innovation is a social influence-driven process of penetration in the market by new products \& services. Besides, it was stated that "diffusion is the process taking place over time with antecedent conditions and adoption \& consequences characteristics, wherein four key components, i.e. innovation itself, time, social system and communication channels, play a key role" (Chigona \& Licker, 2008).

Raban and Koren (2012) expanded that diffusion in DOI is "a process of communicating the innovation over time through certain channels among members of the social system".

Baudisch and Grupp (2006), and Raban and Koren (2012) expressed that "diffusion is a special communication as it spreads new ideas".

Musa (2012) highlighted that diffusion talks about to spreading of technological knowledge/change into several floods of financial exercises which grows space for additional innovativeness enhancing the chain instrument of development advancement dissemination. Innovation is the pivot of this chain relationship inspiring inventions \& motivating diffusion.

\section{Connotation of Innovation Diffusion}

Robinson (2009) asserted that 'Innovation Diffusion' explains how the population takes the innovation and offers three valuable insights in the social change process as:

- $\quad$ "What qualities an innovation spread makes?"

- $\quad$ "The importance of peer network and peer-peer conversation"

- $\quad$ "Understanding different users segments' needs"

Also, Peres et al. (2010) elaborated that "innovation diffusion is a process wherein some social system's members adopt initially an innovation, and then over time more members adopt and finally all (or most) individuals adopt the new idea". Inman (2000) is of the view about technology innovation's diffusion that innovation doesn't take away or include something yet makes a huge difference. Chew et al. (2004) and Murray (2009) asserted that diffusion is the process of communication innovation through some channels among social system members over time. Murray (2009) stated that "innovation diffusion theory explains the process of spreading of new practices, new ideas, or new technologies into a social system".

\section{Innovation is the Process}

Okpara (2007) revealed that innovation is the introduction of some different or new thing, implementation of some creative inspiration. The National Innovation Initiative (NII) defined innovation as "the intersection of invention \& insight, leading to the creation of economic \& social value." Innovation is value - value creation, value-adding to customers' satisfaction - delighting the customer" innovation is the basis of competitive advantages, the technology utilization method, the means of anticipation \& fulfilling needs of customers. Okpara (2007) further asserted that innovation is transforming the best ideas into new value $\&$ reality generating a progression of creative functions. Advancement is joining the cycle of information and thoughts into net worth and without development enterprise it and its provided products become obsolete quickly. By innovation process entrepreneur converts opportunities of market into profitable, workable \& marketable ideas. Innovation is the presentation of imaginative things having noteworthy effects on industry, an organization, and society.

The innovation process consists of the below-given steps mentioned by Robinson (1967) originally Usher proposed four innovation process steps.

1 - Problem Perception - Existence of problem must be felt an innovation to occur

2 - $\quad$ Stage Setting - some particular events configuration is brought together

3 - The act of insight - Solution is found here. Insight is needed because of uncertainty

4 - The critical revision - The innovation is analyzed for determining its practicality However MacVaugh and Schiavone (2010) also consider diffusion of innovation as a "bandwagon" process creating inside an interpersonal organization, and depending on its complementary infection between its "peer" hubs. Social contagion is a procedure wherein a person adopted a behavior or an idea from someone else. Learning is a multistep social process in which 
individuals acquire a progression of creative functions. Advancement is consolidating the cycle of information and thoughts into net worth and without development. However, innovation's adopters must be capable of absorbing \& applying external knowledge for utilizing new technology. The extent of absorptive capacity of the single user may affect his learning of using new technology positively and making the retiring to existing technology less difficult. Furthermore, the switching costs extent reasonable to possible adopter of innovation to gain proficiency with the using of new one relies upon how much endeavors and time adopter spent on learning to utilize the old technology \& its feature.

Hana (2013) extracting from several researches opined to divide the innovative process into two essential parts. The first part is inventive - concerning with original idea, concept, or thought generation - and the second is innovative, wherein the invention is implemented \& marketed. Thus in the organization innovation is a consequence of the creativity of employees bringing added value and must have customers as its target.

Musa (2012) quoting the formula "invention-innovation-diffusion mechanism" asserted that "technological change happens through a chain relationship process of three steps" - invention, innovation \& diffusion. "Invention is an item creation based on original knowledge \& ideas usually called as "breakthrough" technology. Diffusion is spreading of technological knowledge among various economic activities expanding the space of further creativity of amplifying the chain mechanism of invention-innovation-diffusion". Innovation is the pivot chain relationship because of inspiring invention and motivating diffusion so invention \& diffusion both have some attributes.

Decision-Making Stages and Process of Diffusion of Innovation

Bertrand (2004) expressed that process of innovation-decision is an over-time sequence and target audience members pass through it. This is a five-stage sequence: (1) Awareness, (2) Knowledge, (3) Persuasion, (4) Adoption, and (5) Implementation.

Dick (2002); Peansupap \& Walker (2006); Sahin (2006); Chaipoopirutana et al (2009) and KOCAK et al. (2013) described the "innovation-decision process as an information-seeking \& information-processing activity where individuals are motivated for reducing uncertainty about advantages \& disadvantages of an innovation. The researchers quoted innovation-decision steps following each other in time-order manner as: (1) Knowledge, (2) Persuasion, (3) decision, (4), implementation and (5) confirmation".

Neudorfer (2004) revealed that individuals at the knowledge stage first time notices the innovation's existence. This occurs by some coincidence or arranged because of an intentional quest for an item or administration having specific characteristics. In the persuasion stage, the individuals try to determine the cost $\&$ benefits of the innovation due to further information about the product $\&$ service. In the positive evaluation function of development, it will be tried out, and relying upon the test results, the individuals decide whether to purchase \& use the innovation or not, this is the "Decision Stage". In the usage Stage, the advancement is utilized. Meanwhile, individuals experience whether the innovation can be positive which is leading to purchase decision confirmation (Confirmation Stage). This results in activities like purchasing again the same product.

Explaining the diffusion of innovation stages Sahin (2006) and KOÇAK et al. (2013) expressed that in innovation case, first is the knowledge stage, where adopters must recognize the innovation quantity to be secured and how it is used, and so on. Second is the persuasion stage wherein adopters want to know the answers to the questions such as "what are innovations' consequences?" and what advantages \& disadvantages would be in any situation of this innovation? This means adopters would be psychologically more involved at the persuasion stage (Bernik, Azis, Kartini, \& Harsanto, 2015). After these stages, individuals face the decision of rejection or adoption of innovation.

Sahin (2006) explaining these five stages expressed that the innovation-decision process begins with the knowledge stage where individuals learn about innovation's existence and search for information about it. "What?" "Why?" \& "How" are the questions at the knowledge stage. Question form three types of knowledge: (1) Awareness knowledge, (2) How-to-knowledge \& (3) Principles knowledge.

- $\quad$ Awareness knowledge represents the innovation's existence and motivates the individual to seek more information about innovation to adopt it. 
- How-to-knowledge informs about the ways of correct utilization of innovation. This knowledge is a necessary variable of adoption decisions.

- $\quad$ Principles knowledge includes the principle of functioning describing why \& how innovations work. Without knowledge, innovations can be adopted but its misuse would lead to its discontinuance. During the persuasion stage, the attitude of individuals towards innovation may be positive or negative. The persuasion stage is feelings centered stage so at this stage individuals are involved stage more sensitively. At the decision stage, individuals choose to reject or adopt the innovation. If innovation is adopted partially on a trial basis, usually it is adopted more quickly because many individuals first try the innovation in their situation and then make a decision of rejection or adoption. However, rejection is possible at every stage of the decision process. Sahin (2006) identified two types of rejection 1 - Active rejection 2 Passive rejection. Inactive rejection individuals try the innovation and think about adopting it but later decide not to adopt it. In a passive rejection position, the individuals do not think to adopt the innovation at all. The order is knowledge-persuasion-decision. Then implementation stage wherein an innovation is put into practice. The order is knowledgepersuasion-decision. Then stage of implementation wherein an innovation is implemented in practice. However, innovations bring newness in which some degree of uncertainty is involved in diffusion. Thus to reduce the uncertainty the implementers need technical assistance from the change agent. Re-invention happens usually at the stage of implementation, so implementation is a vital stage. Innovation is the process of new idea creation or discovering, while innovation adoption is the process of using the existing idea. The more re-inventions take place, the more quickly a development is received and gets regulated. As advancements, PCs are the devices that comprise of a few applications and openings, so PC advances are more helpless against reexamination. The last stage of diffusion is the confirmation stage. In the confirmation stage, the individuals look for support for their decision. The confirmation stage is the last stage in which individuals look for support for their decision. This can be reversed if the individuals about innovation receive conflicting messages however individuals seek supporting messages and try to stay away from conflicting messages.

Peansupap \& Walker (2006) mentioned from literature ten stages of diffusion of innovation i.e. (1) - idea conception, (2) - awareness, (3) - matching, (4) - appraisal, (5) - persuasion, (6) adoption, (7) - implementation, (8) - confirmation, (9) - routinization and (10) - infusion. However about organizations Peansupap \& Walker (2006) believe that adoption and its implementation in organizations has six stages i.e. (1) - initiation, (2) - adoption, (3) - adaptation, (4) - acceptance, (5) routinization, (6) - infusion. This stage model based on each stage's characteristics has been utilized for estimating innovation reception development. The first stage, initial adoption, focuses on innovation's diffusion at the organizational level consisting of three sub-processes: knowledge awareness; persuasion, and adoption decision. The second stage, actual implementation, focuses on group or individual adoption and diffusion.

Neudorfer (2004) mentioned perceived risk as a relevant product quality besides the above points. This criterion describes the insecurity attached to this innovation. Adaptation theory explains individuals' behavior in dealing with innovations and diffusion theory examines the diffusion of innovations in a social system concerning time. So the diffusion research object is the adoption speed of innovation on the time.

\section{Factors Influencing the Innovation Diffusion Process}

Chigona and Licker (2008) expressed that one step towards maximizing innovation's adoption rate is to understand the adoption influencing factors. According to Valente (1996), individuals are different in their willingness of taking risk in getting a new product or idea. Who will take risks and who will not? How social systems influence them. "A social system is the pattern of friendship, communications or support, advice, which exists among its members". Individuals having the highest number of nominations were opinion leaders and were theorized to have a significant influence on the rate of adoption. According to the second or another approach within a system, weak ties are necessary across subgroups for happening diffusion. Third network diffusion approach, suggesting structural equivalence. Structural equivalence affected the adoption of innovation. Other factors 
affecting the diffusion of innovation are density, centrality \& reciprocity. Two external sources are influencing the innovation adoption i.e. 1 - cosmopolitan actions \& 2 - communication media. These tell individuals earlier awareness of innovation \& independence from framework standards empowering them to be prior adopters and defenders of development. In craftsmanship and science networks the standard is for inventive conduct where outside impact works suddenly.

According to Sahin (2006), an important obstacle to innovation adoption is uncertainty. The consequences of innovation may create uncertainty. Consequences are the change occurring in a social system or an individual as a result of innovation rejection or adoption. To reduce uncertainty an individual should be informed about the consequences of adoption. Consequences are classified as desirable \& undesirable; direct \& indirect, and anticipated \& unanticipated.

\section{Adoption of Innovation}

Ling and Nasurdin (2010) expressed that in the manufacturing field, to keep up with fast changes in the global market \& technology, firms have been enhancing their capabilities, especially during the last few decades. The increase in environmental uncertainty compelled the organizations to be cost proficient and skilled in the conveyance of predominant client esteem. Numerous explores featured the critical job measure and item development played in this regard.

Okpara (2007) pointed out that until widely adopted \& incorporated in daily life any idea does not become an innovation because people in the majority resist the change. Hence a key part of innovation is to convince others that this is a good idea.

Neudorfer (2004) asserted that many factors influence the adoption process concerning duration \& course. So "environment-specific, product-specific \& innovation- specific forces are mention in literature". Product-specific factors are innovation qualities to which individuals can perceive subjectively. These qualities influence the intensity \& adoption's timely outcome.

Delre et al. (2006) narrated expressing diffusion process that some early adopters adopt the innovation fashion trend, influenced easily by new trends all potential consumers decide to adopt \& laggards and skeptical consumers also may decide to conform to adopt the new product. The social influence of the behavior of other consumers affects constantly throughout this process of individual adoption.

Baudisch and Grupp (2006) expressed that social scientist thinks that adoption of an innovation is not an instantaneous decision but it is process over time. During this process an individual passes through the stages: 1 - first the innovation knowledge, 2 - making an attitude towards innovation, 3 - decision to reject or adopt the innovation, 4 -implementation of new idea, and 5 - finally the confirmation of this decision. Its conceptualization consists of five stages.

Chiagona and Licker (2008) revealed that innovation is perceived useless if not adopted despite being well designed. So those who are responsible for innovation should its adoption rate, and the first step of maximizing the adoption rate of innovation is to understand the factors influencing the adoption.

Chew et al. (2004); Baudisch and Grupp (2006), and Stephenson et al. (2017) quoted and elaborated five different characteristics or attributes of innovation contributing to its adoption rate include:

1 - Compatibility - Degree of perceiving the innovation consistent with the existing values

2 - $\quad$ Trialability - Degree to which innovation is experimented with on a limited basis

3 - $\quad$ Relative advantage - Degree of perceiving the innovation better than the idea it supersedes

4 - $\quad$ Observability - Degree of visibility of results of an innovation to others

5 - $\quad$ Complexity - Degree of perceiving the innovation as relatively difficult to understand \& use

Chaipoopirutana et al. (2009), Sain (2006), and Stephenson et al. (2017) stated that innovations are adopted fast having more simplicity, compatibility, relative advantage, observability $\&$ trialability. Innovation's rate of adoption is determined by variable: innovation-decision, innovation attributes, nature of the social system, medium of communication, and promotion efforts of change agents. Despite having obvious advantages, the adoption of a new idea is difficult, so the accessibility of these advancement factors accelerate the cycle of dispersion of development. Various adopters' categories are: Innovators, early adopters, early majority, late majority \& laggards.

MacVaugh and Schiavone (2010) indicated three common players in any innovation diffusion system, which are: the innovating market or industry, the users community (having categorically alike technology), and the individual (potential) users. The players are influenced by or influence three 
systematic conditions: social, technological \& learning. Conditions influence many levels, distinguished as a variable related to selection/non-reception.

Moschini (2000) also had pointed out another fact that market power affects the price charged for innovation inputs and in turn pricing of innovation influences its adoption resulting in social \& private costs and benefits.

\section{Four Key Terms as Major Elements of Diffusion}

Inman (2000), Bertrand (2004), Sahin (2006) \& KOCAK et al. (2013) declared four key components $\&$ factors influencing the diffusion process: 1 - innovation itself; 2 - communication channels; 3 - time $\& 4$ - social system wherein innovation is introduced.

Murray (2009) also mentioned these four main elements put forward by Rogers In 2003 i.e. 1 - Innovation, 2 - Channels of Communication, 3 - Time \& 4 - Social System.

\section{1- Innovation Itself}

Baudisch and Grupp (2006); Chew et al. (2004), and KOCAK et al. (2013) indicated that in diffusion process innovation itself is also an important factor. KOCAK et al. (2013) quoted Rogers et al (n.d.) who mentioned that scholars also studied why some innovations relatively spread rapidly while others spread slowly. Innovations perceived: 1 - relatively advantageous, 2 - are compatible with existing values, \& experience 3 - relatively easy to adopt and comprehend, 4 - observable \& tangible, and 5 - divisible for trial, are more rapidly adopted. Sahin (2006) stated that innovations offering relatively more advantage, simplicity, compatibility, trialability \& observability are adopted faster than other innovations. However adoption of new ideas, despite having obvious advantages, new ideas are difficult to adopt. Wejnert (2002) narrated that most diffusion analyses emphasized actors \& their innovation perceptions, along with environmental context variables influencing the adoption process. However, authors commonly consider two innovation associated factors: Public versus Private consequences, $\&$ cost versus benefit. Public versus private consequences refer to the adoption of innovation's impact on other than public consequences (actors) versus that on private consequences (actors itself). Innovation adoption with public consequences leads to historical breakthrough reforms e.g. welfare policy, civil right protecting laws patent laws \& international regulations for natural environment protection, whereas innovations with private consequences impact the well-being of peer groups, organizations, \& rural communities. These innovations improve the quality of lives of individuals or reform the social structure or organizations e.g. new medical practices, fertility control methods, improving management style, or agriculture technology improvement.

\section{2- Communication Channels}

China and Licker (2008) squeezing from some researches expressed that an innovation can be communicated through interpersonal communication or mass media. These two channels or media play roles complementary but different. However, despite individuals know about an innovation via channels of mass communication but adoption decisions are made influenced by interpersonal communication. Under DoI many effects of characteristics of innovation are moderated actually by role others role or presence: Observe-ability depends on result communication ability to others, relative advantages depend upon task \& its definition, trial-ability depends on social circumstances of trial, complexity depends on the ability to talk to oneself. Sahin (2006) referring to some studies narrated that a channel is the means of sending or communicating a message from source to receiver. "Innovation is a specific communication which includes communication elements: 1- innovation, 2 two individuals or other adopting units, 3 - and a channel of communication". Interpersonal communication or mass media are two channels of communication. Mass media include radio, TV, newspapers, and interpersonal channels is consisting of two-way communication between individuals. On the other hand "diffusion is a very social process involving interpersonal communication relationships". Therefore interpersonal channels are more powerful to change or create a strong attitude held by individuals. Inman (2000) asserted that the nature of the relationship of information exchange between individuals determines the conditions wherein a source will transmit innovation to the receiver or not and transfer's effects. Mass Media has a tremendous and problematic influence on innovations and alters the communication dynamic by influencing the stakeholders. However, mass media is considered an element of innovation. Tolba and Mourad (n.d.) expressed that empirically it is proved that opinion leaders affect the consumer decision-making process through spreading positive words of mouth which influences diffusion rate. 


\section{3- $\quad$ Time}

Inman (2000) asserted that in technological progress time plays a critical role because it defines the position individual occupy during the evolution of progress and the pace at which this progress occurs. By the time there are five categories of adopters i.e. innovators, early adopters, early majority, late majority, and laggards. Sahin (2006) mentioned that in most behavioral researches time aspects are ignored while including time dimension in process of diffusion illustrates its strength. The adopter categorization innovation diffusion process $\&$ adoption rate all include a time dimension.

\section{4 - $\quad$ Social System}

Inman (2000) and Sahin (2006) quoted social system definition as: "a set of inter-related units involved in joint problem solving for accomplishing common goals". Since any innovation diffusion takes place in a social system so it will be influenced by the social structure of the social system. The structure of the social system is the patterned arrangements, of units in it. The social system's nature influences the innovativeness of individuals, which is the main criterion for adopters' categorization. Two roles in innovation introduction \& adoption in any social system are especially important. First is the "opinion leader" who imagines anyone who can influence others. The second is the "change agent". Individuals associated with any adoption of decisions are agents. There are three potential descriptors in the social system. First is attractive versus unwanted relying upon impacts of advancement in a social framework are broken or practical. The second type is Direct versus indirect, and the third type is anticipated versus unanticipated. Secondly direct versus indirect depends on whether changes to a social system or an individual are occurring in reply to an innovation or happening as a second-order result of direct inferences of an innovation. Thirdly depends on whether changes are intended $\&$ recognized by a social system's members or not.

Besides the above listed four characteristics, Wejnert (2002) has also mentioned the characteristics of innovations as one more element.

\section{5 - Characteristics of Innovations}

Wejnert (2002) revealed that usually innovation's actors or characteristics which may influence substantially the perception of benefits \& costs of innovation are ignored, thus merging with innovation's characteristics per se. Wejnert (2002) mentioned six variables' sets appearing to modulate innovations' adoption. These sets of variables are: 1 - innovation's social entity, 2- familiarity with the innovation, 3 - socioeconomic characteristics, 4- Status characteristics, 5 - relative position in the social network and 6 - personal characteristics associated with cultural variables, modifying actors' personality characteristics at the population level.

\section{Conclusion}

From the study of the above-quoted literature, it is concluded that innovation is an object, idea, or practice to which individual or adoption units perceive as new centering on, process, people, technology, structure, new behavior and culture, deployed in commercial use for driving economic growth. Innovation is also analyzing \& combining some concepts and creating new concepts \& new thinking not available previously. Innovation is successfully developing the competitive advantage which, means it is key to entrepreneurship. For an innovation, it is not necessary to be new but instead of this, it must be supposed as new by would-be adopters. Innovation instead of any mechanical creation can be an idea, new production process technology, new product or service, new program or plan about members of organization, new administrative system integrated \& perceived to have value. However, innovation becomes beneficial only when it is diffused through communication over time through certain channels among the social system members. The best measure of innovation's economic consequences is productivity growth, and economists have concluded that innovation is a key to enhancing prosperity \& improving living standards.

\section{References}

Abou-Moghli, A. A., Ghaith, M., Al Abdallah, \& Ayed, M. (2012). Impact of innovation on realizing competitive advantage in the banking sector in Jordan. American Academic \& Scholarly Research Journal, 4(5), 30-33.

Akram, K., Suleman, H. S., Muhammad, A. N., Tauqir, A. G. \& Amjad, K. H. C. (2011). Role of knowledge management to bring innovation: An integrated approach. International Bulletin of Business Administration. 92(11), 121-134.

Almeida, J. P. L., Farias, Josivania, S., \& Carvalho, H. S. (2017). Drivers of the technology adoption in healthcare. Brazilian Business Review, 14(3), 336-351. 
Atkinson, R. \& Wial, H. (2008). Boosting productivity, innovation, and growth through a national innovation foundation. The Blueprint Policy Series Brookings. Washington, DC, WA: ITIF.

Baudisch, A. F. \& Grupp, H. (2006). Evaluating the market potential of innovations: A structured survey of diffusion models. Retrieved from www.wiwi.uni-jena.de

Bernik, B., Azis, Y., Kartini, D., \& Harsanto, B. (2015). Managing innovation of SMEs in the creative industry for interactive game subsector and TV and Radio subsector based on local wisdom in the development of competitiveness business (Case Study SMEs in Bandung). International Journal of Business and Administrative Studies, 1(2), 49-53. Doi: https://doi.org/10.20469/ijbas.10001-2

Bertrand J. T. (2004). Diffusion of Innovations and HIV/AIDS. Journal of Health Communication, 9 , 113-121.

Bitter-Rijpkema, M., Peter, B., \& Jansen, D. (2003). Learning to change: The virtual business learning approach to professional workplace learning. Educational Technology \& Society. 6(1), 20-23.

Chaipoopirutana, S., Combs, H., Chatchawanwan, Y. \& Vij, V. (2009). Diffusion of innovation in Asia: A study of internet banking in Thailand and India. Innovative Marketing, 5(4), 10-19.

Chew, F., Grant, W., \& Tote, R. (2004).Doctors On-line: Using diffusion of innovations theory to understand internet use. Medical Informatics 36(9), 645-650.

Chigona, W. and Licker, P. (2008) "Using diffusion of innovations framework to explain commercial computing facilities adoption among the urban poor. Information Technologies and International Development, 4(3), 57-73.

Delre, S. A., Jager, W. \& Marco, A. J. (2006). Diffusion dynamics in small-world networks with heterogeneous consumers. Computer Math Organization Theory. New York, NY: Springer Science.

Dick, S. J. (2002). Reconsidering adoption behavior: Models beyond diffusion. The Second International Conference on Electronic Business, Taipei, Taiwan.

Hana, U. (2013). Competitive advantage achievement through innovation and knowledge. Journal of Competitiveness, 5(1), 82-96.

Ibrahim, M. J. (2012). Technological change and economic transformation, technological change. Retrieved from http://www.intechopen.com/books/technological-change/technologicalchange-and-economic-transformation

Inman J.A. (2000). The Importance of Innovation: Diffusion theory and technological progress in writing centers. The Writing Center Journal, 21(1), 20-23.

Koçak, N. G., Kaya, S., \& Erol, E. (2013). Social media from the perspective of diffusion of innovation approach. The Macro-Theme Review, 2(3), 13-18.

Ling, T. C. \& Nasurdin, A. M. (2010). The influence of knowledge management effectiveness on administrative innovation among Malaysian manufacturing firms. Asian Academy of Management Journal, 15(1), 63-77.

MacVaugh, J. \& Schiavone, F. (2010). Limits to diffusion of innovation - A literature review and integrative model. European Journal of Innovation Management, 13(2), 197-221.

Mark, G. \& Poltrock, S. (2001). Diffusion of a collaborative technology across Distance. Proceedings of the 2001 International ACM SIGGROUP Conference on Supporting Group Work. New York: ACM Press.

Mohamad, N. \& Backhouse, C. (2014). A framework for the development of halal food products in Malaysia. Proceedings of the International Conference on Industrial Engineering and Operations Management, Bali, Indonesia.

Moschini, G. C. (2000). Economic benefits and costs of biotechnology innovations in agriculture (CARD working paper 01-WP 264). Ames, Iowa: Center for Agricultural and Rural Development.

Murray, C. E. (2009). Diffusion of innovation theory: A bridge for the research-practice gap in counseling. Journal of Counseling \& Development, 87, 12-19.

Neudorfer, R. (2004). Critical success factors for the management of innovative mobile business models. 6th Undergraduate and Graduate Students e-Conference.

Okpara, F. O. (2007). The value of creativity and innovation in entrepreneurship. Journal of Asia Entrepreneurship and Sustainability, 3(2), 101-107. 
Peansupap, V. \& Walker, D. H.T. (2006). Innovation diffusion at the implementation stage of a construction project: A case study of information communication technology. Construction Management and Economics, 24, 321-332.

Peres, R., Muller, E. \& Mahajan, V. (2010). Innovation diffusion and new products growth models: A critical review and research directions. International Journal of Research in Marketing, 27, 97-106.

Raban, D. \& Koren, H. (2012). Is reinvention of information a catalyst for critical mass formation? Proceedings of the Chais Conference on Instructional Technologies Research. Learning in the Technological Era, Raanana, Israel.

Reamer, A. (2014). The Impacts of technological invention on economic growth - a review of the literature. The George Washington Institute of Public Policy/ Lemelson, Foundation of Portland, Oregon.

Robertson, T. S. (1967). The process of innovation and the diffusion of Innovation. Journal of Marketing, 31, 14-19.

Robinson, L. (2009). A summary of diffusion of innovation. Changeology. Amazon.

Sahin, I. (2006). Detailed review of Rogers' diffusion of innovations theory and educational technology-related studies based on Rogers' theory. The Turkish Online Journal of Educational Technology, 5(2), 56-59.

Sengphet, P., Hui, L., \& Phong, L. B. (2019). The pathway to improve innovation capacity for Lao firms: The roles of transformational leadership and psychological resources of employees. International Journal of Business and Administrative Studies, 5(2), 224-239. Doi: https://dx.doi.org/10.20469/ijbas.5.10004-4

Shapiro, H., Haahr, J. H., \& Bayer, I. (2007). Background paper on innovation and education. Taastrup, Denmark: Danish Technological Institute and Patries Boekholt Technopolis.

Stephenson, R, Phelps, A., \& Colburn, J. (2017). Diffusion of innovations and program implementation in areas of health behavior/education/promotion, physical activity, and physical education. DOI REVIEW Journal of Research, 10(1), 1-13.

The Young Foundation (2012). Social innovation overview: A deliverable of the project: The theoretical, empirical, and policy foundations for building social innovation in Europe. European Commission - 7th Framework Program. Brussels, Belgium: European Commission, DG Research

Tolba, A. H. \& Mourad, M. (n.d.). Individual and cultural factors affecting the diffusion of innovation. Journal of International Business and Cultural Studies, 13(4), 1-10.

Valente, T. V. (1996). Social network thresholds in the diffusion of innovations. Social Network, 18, 69-89.

Vargas-Hernandez, J. G., \& Gonzalez, O. C. V. (2020). Innovation in Utility Craftsmanship: Analysis Based on Human Capital. International Journal of Business and Economic Affairs, 5(1), 4250. Doi: https://doi.org/10.24088/ijbea-2020-51005

Wejnert, B. (2002). Integrating models of diffusion of innovations: A conceptual framework. Annual Reviews of Sociology, 28, 297-326. 